\title{
Prevalence and Determinants of Appropriate Health Seeking Behaviour among Known Diabetics: Results from a Community-Based Survey
}

\author{
Sheleaswani Inche Zainal Abidin, Rosnah Sutan, and Khadijah Shamsuddin \\ Community Health Department, Medical Faculty, University Kebangsaan Malaysia, Jalan Yaccob Latif, \\ Bandar Tun Razak, Cheras, 56000 Kuala Lumpur, Malaysia \\ Correspondence should be addressed to Rosnah Sutan; rosnah_sutan@yahoo.com
}

Received 11 April 2014; Revised 8 October 2014; Accepted 14 October 2014; Published 11 November 2014

Academic Editor: Toru Mori

Copyright (C) 2014 Sheleaswani Inche Zainal Abidin et al. This is an open access article distributed under the Creative Commons Attribution License, which permits unrestricted use, distribution, and reproduction in any medium, provided the original work is properly cited.

\begin{abstract}
Introduction. Living with diabetes requires patients to have good self-monitoring of their disease and treatment. Appropriate health seeking behavior is important to minimize complications and improve quality of life. Methodology. A community-based, crosssectional study of disease events and experiences from diagnosis to the time of study was conducted among 460 known diabetics in Tanjong Karang district. The aim of this study was to describe the current pattern of health seeking behavior and its determinants among rural communities. Appropriate diabetic health services utilization was defined as using modern treatment either through oral hypoglycemics or insulin injections, obtained from either a public or private health facility. Result. 85.9\% of respondents reported having appropriate health seeking behaviour at the time of the house-to-house community survey. Multivariate logistic regression analysis revealed that appropriate health seeking behaviour was significantly associated with age of respondent, presence of comorbidity, family history of diabetes, distance from health facilities, perceived family support, and history of early treatment seeking at diagnosis and duration of disease. Conclusion. The present population has better appropriate health seeking behavior and provision of knowledge with strong family support in diabetic care which are important in control and prevention of diabetic complication that need to be emphasized.
\end{abstract}

\section{Introduction}

Diabetes is now regarded as a major public health problem all over the world [1]. The prevalence of diabetes mellitus is reaching epidemic levels worldwide $[2,3]$. The World Health Organization (WHO) estimated that the number of people with diabetes mellitus is expected to rise from 171 million in 2000 to 366 million in 2030, as a result of population ageing and urbanization [4]. In Singapore, diabetes mellitus is the 8th leading cause of death with $3 \%$ of all deaths being attributable to diabetes alone $[5,6]$. In Malaysia, the World Health Organisation has estimated that in 2030, our country would have a total number of 2.48 million people with diabetes compared to 0.94 million in 2000 [7]. Prevalence of people with diabetes aged more than 18 years old increased from $11.6 \%$ in 2006 to $15.2 \%$ in 2011 [8].
Health seeking behaviour are directly related to disease incidence, prevalence and complication. Early recognition of symptom, presentation to healthcare facilities, and compliance with effective treatment can reduce morbidity and thereby mortality [9]. Diabetes is a common disease causing significant morbidity and mortality; thus appropriate health seeking behaviour may help to plan diabetes care and management upon diagnosis so that complication can be minimized and quality of life can be improved. Malaysia is currently experiencing a tremendous increase in prevalence of diabetes mellitus, which presents a great challenge to the Ministry of Health, Malaysia, for designing health care policies and programmes.

Health Seeking Behaviour. The definition of health seeking behaviour is often considered vague and difficult to define. 
There is no common definition agreed upon by sociologists in any sociology literature. Different definition may be used in different studies, despite referring to the same activity. According to sociology literature, health care seeking behaviour will be influenced by the individual self, diseases, and the availability and accessibility of health services. Depending on these determinants and their interactions [10, 11], health care seeking behaviour is a complex outcome of many factors operating at individual, family, and community level. Treatment choices would involve many factors related to illness type and severity, sociodemographic characteristics, preexisting lays believe about illness causation, accessibility of treatment available and their perceived efficacy and disease profile [12].

Appropriate health seeking behaviours among people with diabetes in this study are defined as seeking modern/conventional treatment either through oral hypoglycemics or through insulin injections, from public or private health facilities (hospital and clinic) [13]. The use of unconventional treatment is gaining considerable recognition and popularity worldwide. Use of nonmodern/unconventional treatment especially complementary and alternative medicine is common among people with diabetes, and often they may not inform their doctors of their use [12]. It is important to know the usage of unconventional treatment because interaction with conventional treatment may occur. It may even cause severe adverse reaction leading to significant morbidity and mortality [14].

Since the 1970s, the Ministry of Health, Malaysia, has taken important steps to develop a good network of health care services in the country. A total of $97 \%$ of the citizens have access to health services with the majority having access to a health care system within a $3 \mathrm{~km}$ radius from their residence. In East Malaysia, more than 50\% of the rural population has access to health services within a $5 \mathrm{~km}$ radius from their residence [15]. Despite having good network of health care services, prevalence of seeking care for the illness is still low. Among respondents aged 30 years and above, 92.9 percent among people with diabetes are seeking treatment from health facilities whereas 7.1 percent did not seek any diabetic treatment for their diabetic [16].

In Malaysia, information regarding the pattern of behaviour among people with diabetes in seeking health and their utilisation of modern treatment and health facilities is limited. Significant nationwide studies on patterns in utilization of health services and its contributing factors in Malaysia are limited. Research done in 2009 showed that, in health services in Malaysia that are still under utilisation, only 33 percents of respondent had contact with health care professional [17]. Study done by National Health and Morbidity Survey in 2006 also showed similar findings. Only 59.3 percent of respondents are seeking treatment for their illnesses [16]. The objective of this study therefore is to understand current pattern of health seeking behaviour and particularly to determine factors influencing health seeking behaviour known among people with diabetes in Tanjong Karang, Selangor.

\section{Materials and Methods}

2.1. Study Design. A cross-sectional study was conducted in selected communities in Tanjong Karang between October 2011 and April 2012. Tanjong Karang was purposely chosen whereby simple random sampling method was used to choose 17 villages. Household survey was done prior to the study to identify people with diabetes. A simple random sampling was used to select respondents who had diabetes from the household survey.

2.2. Sample Size. The sample size calculations were done using Power and Sample Size Calculation software. A single proportion formula (Fleiss formula) was used. Calculations were done for all possible variables and the biggest sample size was chosen. The minimum sample size required were 460 (precision level of 0.07 , the value of normal standard distribution of 1.96 , power of $80 \%$ ).

\subsection{Inclusion Criteria}

(a) Villagers from Tanjong Karang who self-reported having diabetes mellitus (types 1 and 2).

(b) Age $\geq 18$ years old.

(c) Able to read, write, communicate, and understand Bahasa Malaysia.

(d) Agree to participate

2.4. Data Collection. Data were collected by mean of structured face to face interview. People with diabetes were interviewed using a structured validated questionnaire without disturbance in the privacy of their own homes. In order to validate the content of the questionnaires, comments and suggestions from a group of experts including two public health lecturers and one endocrinologist were reviewed. Following the content validity, face validity was carried out. Ten villagers were interviewed with the questionnaires. A few wordings had been changed after the session to improve the contents of the questionnaires. The questionnaire was then piloted among 40 villagers from Kampung Bestari Jaya, Kuala Selangor. It consists of 59 items grouped into 6 domains composed of six parts which were social demographic profile, disease profile, knowledge of diabetes mellitus, perception of diabetes mellitus, family support, and health seeking behaviour. Result of validation shows that the constructed validity and reliability were optimal. Cranach alpha coefficient values for each domain ranged between 0.6 and 0.9 .

The following operational definitions were used.

Health seeking behaviour was defined as follows: respondent who reported visiting any health facilities (government or private) and using modern treatment (oral hypoglycaemic agent or insulin therapy). Appropriate health seeking behaviours are defined as respondents seeking modern treatment either through oral hypoglycemics or through insulin injections, from a public or private clinic or hospital [13].

2.5. Ethical Approval. This study was reviewed and approved by the Research and Ethics Committee, National University of Malaysia, Grant no. FF-045-2011. 
2.6. Data Analysis. Data entry and statistical analysis were done using SPSS version 20. The continuous variables were recorded as mean and standard deviation (SD). Categorical variables were recorded as frequencies and percentages. Simple logistic regression was used as a screening in selection of variables for further analysis. All variables with $P$ value less than 0.20 and clinically relevant variables were included in the multiple logistic regression analysis. The method that was used for variable selection was enter, backward, and forward stepwise procedure. All possible 2-way interactions were checked and those significant variables were included in the model. The independent variables were fitted into multiple logistic regression and multicollinearity was checked. Fitness of model was tested by Hosmer-Lemeshow goodness of fit test, the classification table, and receiver operator characteristic curve. $P<0.05$ was set as significant level.

\section{Results}

Out of the 506 respondents visited in the survey, there were a total of 460 respondents, giving a response rate of $90.9 \%$.

3.1. Sociodemographic and Disease Profile of Respondents. A total of 460 villagers were interviewed. The mean age of the respondents was $53.5 \pm 13$ years, with slightly more females (62.6\%). The mean households' size was 4 . The median monthly households' income was RM 1000. The majority $(84.3 \%)$ of villagers had formal education up to secondary level. Majority of respondents were Malays (93.5\%), Islam (93.5\%), married (79.1\%), working (32.4\%) and housewife (32.8\%) (Table 1).

The majority of respondents reported having diabetes mellitus less than 5 years $(47.8 \%)$. Most of the respondents were having comorbidity (61.5\%) and close family members diagnosed with diabetes mellitus (54.3\%). $27 \%$ of respondents reported their diabetes being diagnosed by opportunistic medical screening at health facilities and only $26.5 \%$ by their own initiatives going to health facilities for medical screening.

Table 2 shows the current pattern of health seeking behaviour. Appropriate health seeking behaviour were classified as respondents seeking treatment within 24 hours upon diagnosis, utilizing health facilities and using modern treatment. Reason for not seeking medical treatment included, able to treat themselves, no time and financial constraints.

Table 3 showed that age of respondent, marital status, educational attainment, employment status, household income, household size, distance from health facilities, transportation, duration of illness, present of co-morbidity, family history of Diabetes mellitus, duration of seeking treatment upon diagnosis, level of family support and perception of diabetes mellitus were associated with health seeking behaviour.

Table 4 presented the adjusted odds ratio for likelihood of appropriate health seeking behaviour. When all predictive variables from the Bivariate analysis were entered in the multivariate analysis, absence of comorbidity (OR 3.15, 95\% CI 1.66-5.98), seeking treatment within 24 hours of diagnosis (OR 2.62, 95\% CI 1.35-5.07), duration of illness less than 5 years (OR 3.40, 95\%CI 1.69-6.08) and those having high
TABLE 1: Sociodemographics and disease profile of the respondents $(N=460)$.

\begin{tabular}{|c|c|c|}
\hline Characteristics & $n=460$ & $(\%)$ \\
\hline \multicolumn{3}{|l|}{ Gender } \\
\hline Male & 172 & 37.4 \\
\hline Female & 288 & 62.6 \\
\hline \multicolumn{3}{|l|}{ Ethnic } \\
\hline Malay & 430 & 93.5 \\
\hline Chinese & 21 & 4.6 \\
\hline Indian & 9 & 1.9 \\
\hline \multicolumn{3}{|l|}{ Religion } \\
\hline Islamic & 430 & 93.5 \\
\hline Hindu & 21 & 4.6 \\
\hline Buddha & 9 & 1.9 \\
\hline \multicolumn{3}{|l|}{ Occupation } \\
\hline Working & 149 & 32.4 \\
\hline Unemployed & 85 & 18.5 \\
\hline Housewife & 151 & 32.8 \\
\hline Pensioners & 70 & 15.2 \\
\hline Students & 5 & 1.1 \\
\hline \multicolumn{3}{|l|}{ Education } \\
\hline No education & 73 & 15.9 \\
\hline Primary school & 155 & 33.7 \\
\hline Secondary school & 182 & 39.6 \\
\hline University/college & 50 & 10.9 \\
\hline \multicolumn{3}{|l|}{ Marital status } \\
\hline Bachelor & 13 & 2.8 \\
\hline Married & 364 & 79.1 \\
\hline Widowed & 23 & 5.1 \\
\hline Divorced & 60 & 13.1 \\
\hline Duration of illness & Mean $\pm(\mathrm{sd}) 7.28(5.65)$ & \\
\hline Less than 5 years & 220 & 47.8 \\
\hline $5-10$ years & 120 & 26.0 \\
\hline $11-19$ years & 98 & 21.4 \\
\hline$>20$ years & 22 & 4.8 \\
\hline \multicolumn{3}{|l|}{ Comorbidity } \\
\hline Yes & 283 & 61.5 \\
\hline No & 177 & 38.5 \\
\hline \multicolumn{3}{|c|}{ Complication of diabetes mellitus } \\
\hline Yes & 198 & 43.0 \\
\hline No & 262 & 57.0 \\
\hline \multicolumn{3}{|c|}{ Family history of diabetes mellitus } \\
\hline Yes & 250 & 54.3 \\
\hline No & 210 & 45.7 \\
\hline
\end{tabular}

family support (OR 2.56, 95\%CI 1.25-7.69) were determinants for appropriate health seeking behaviour.

\section{Discussion}

The prevalence of appropriate health seeking behaviour among people with diabetes in Tanjong Karang, Selangor, was $14.6 \%$. There is no reported study on the prevalence 
TABLE 2: Current pattern of health seeking behavior.

\begin{tabular}{|c|c|c|}
\hline Characteristics & $n$ & $\%$ \\
\hline \multicolumn{3}{|l|}{ Method of DM being diagnosed } \\
\hline Medical screening at community level & 30 & 6.5 \\
\hline Medical screening at health facilities & 124 & 27.0 \\
\hline Own initiatives & 122 & 26.5 \\
\hline Medical checkup (preemployment/hajj) & 36 & 7.8 \\
\hline Getting treatment for symptom of DM & 69 & 15.0 \\
\hline Admitted to hospital due to complication of DM & 47 & 10.2 \\
\hline Medical screening 6 weeks postpartum. & 32 & 7.0 \\
\hline \multicolumn{3}{|l|}{ Seeking treatment upon diagnosis } \\
\hline Yes & 376 & 81.7 \\
\hline No & 84 & 18.3 \\
\hline \multicolumn{3}{|l|}{ Early treatment at diagnosis } \\
\hline Within 24 hours & 222 & 48.3 \\
\hline After 24 hours & 154 & 33.4 \\
\hline \multicolumn{3}{|l|}{$\begin{array}{l}\text { Reason for not/delay in seeking treatment upon } \\
\text { diagnosis }\end{array}$} \\
\hline $\begin{array}{l}\text { Financial constraint (transport, medicine, and } \\
\text { consultation) }\end{array}$ & 46 & 10.0 \\
\hline No time & 114 & 24.8 \\
\hline Distance from health facilities & 26 & 5.7 \\
\hline $\begin{array}{l}\text { Considered that symptoms were not serious } \\
\text { enough for treatment }\end{array}$ & 27 & 5.9 \\
\hline Self-treatment & 206 & 44.8 \\
\hline No treatment & 5 & 1.1 \\
\hline$>2$ reasons & 36 & 7.8 \\
\hline \multicolumn{3}{|l|}{ Utilizing health facilities } \\
\hline Government hospital & 263 & 57.2 \\
\hline Private hospital & 23 & 5.0 \\
\hline Government clinic & 114 & 24.8 \\
\hline Private clinic & 13 & 2.8 \\
\hline Pharmacy/Chinese shop & 7 & 1.5 \\
\hline Traditional healers & - & - \\
\hline Homeopathy healers & 2 & 0.4 \\
\hline Self-treatment & 30 & 6.5 \\
\hline No treatment & 8 & 1.7 \\
\hline \multicolumn{3}{|l|}{ Using modern treatment } \\
\hline Oral diabetic agent & 308 & 67.0 \\
\hline Insulin & 43 & 9.3 \\
\hline Oral diabetic agent and insulin & 53 & 11.5 \\
\hline Traditional medicine & 4 & 0.9 \\
\hline Homeopathy medicine & 3 & 0.7 \\
\hline Food supplement & 7 & 1.5 \\
\hline Medicine bought from pharmacy & 3 & 0.7 \\
\hline Medicine bought from Chinese shop & 6 & 1.3 \\
\hline Self-treatment & 23 & 5.0 \\
\hline No treatment & 10 & 2.2 \\
\hline \multicolumn{3}{|l|}{ Health seeking behaviour } \\
\hline Appropriate & 395 & 85.9 \\
\hline Inappropriate & 65 & 14.1 \\
\hline
\end{tabular}

of appropriate health seeking behaviour among people with diabetes in Malaysia. However, the findings are comparable with few studies done in developed and developing countries $[18,19]$. A study done by Khongbuh et al., 2005 showed 63.4 $\%$ from 495 respondent sought treatment for their diabetics from different type of practitioner [18]. A qualitative study done by Hjelm and Atwine in Uganda also showed that healthcare were mainly sought among doctor and nurses in the professional sector [19].

This study also showed that utilizing the health facilities $(89.8 \%)$ and using modern medicine $(87.8 \%)$ for treatment of people with diabetes in Tanjong Karang are still low. This finding is discordant with a previous national study in 2011 where utilizing health facilities (96.9\%) and using modern medicine (94.2\%) are high [3]. The different observe here most probably due to the differences in methodologies (different approach in data collection, study population, location of studies, and difference in definition of health seeking behaviour).

Previous studies had proved that certain patient and disease factors can predict appropriate health seeking behavior [20, 21]. Gender, age, racial group, income, educational level, and presence of chronic disorder are some predictive factors. The present study has demonstrated that age of respondents, educational level, employment status, mean household income, duration of illness, presence of other illnesses, close family having history of diabetes mellitus, duration of seeking treatment upon diagnosis, family support, and perception severity of disease were determinants of appropriate health seeking behaviour. However, on multivariate analysis, presence of other illnesses, having close family members diagnosed with diabetes mellitus, duration of illness more than 5 years, duration of seeking treatment within 24 hours of diagnosis, and high family support remained as determinants of appropriate health seeking behavior. These findings are comparable with other studies done in the Western population [20] and Asian population [21].

There is a need to have an information regarding health seeking behaviour among people with diabetes particularly related to utilization of health facilities and consuming modern medicine. The information is crucial in order to develop strategies for prevention of complication and adaptation to the treatment. The association of appropriate health seeking behaviour with family members having diabetes mellitus and family support found in this study highlight the potential importance of family empowerment in promoting appropriate health seeking behaviour among people with diabetes.

\section{Conclusion}

This study revealed that prevalence of seeking appropriate health treatment among people with diabetes in Tanjong Karang, Selangor, is still low. Presence of other illnesses, having close family members diagnosed with diabetes mellitus, duration of illness more than 5 years, duration of seeking treatment within 24 hours of diagnosis, and high family support are determinants of appropriate health seeking behaviour. 
TABLE 3: Factors associated with appropriate health seeking behaviour.

\begin{tabular}{|c|c|c|c|c|}
\hline \multirow{2}{*}{ Variables } & \multicolumn{2}{|c|}{ Health seeking behaviour } & \multirow{2}{*}{$\chi$} & \multirow{2}{*}{$P$ value } \\
\hline & Appropriate $(n / \%)$ & Inappropriate $(n / \%)$ & & \\
\hline \multicolumn{5}{|l|}{ Age (years) } \\
\hline$<35$ & $364(88.3)$ & $48(11.8)$ & \multirow{2}{*}{18.725} & \multirow{2}{*}{$<0.001$} \\
\hline$\geq 35$ & $31(64.6)$ & $17(35.4)$ & & \\
\hline \multicolumn{5}{|l|}{ Sex } \\
\hline Male & $147(85.5)$ & $25(14.5)$ & \multirow{2}{*}{0.283} & \multirow{2}{*}{0.595} \\
\hline Female & $248(86.1)$ & $40(13.9)$ & & \\
\hline \multicolumn{5}{|l|}{ Marital status } \\
\hline Married & $307(84.3)$ & $305(83.8)$ & \multirow{2}{*}{3.786} & \multirow{2}{*}{0.052} \\
\hline Not married (bachelor, widow) & $88(11.7)$ & $88(91.7)$ & & \\
\hline \multicolumn{5}{|l|}{ Educational level } \\
\hline High & $190(81.9)$ & $42(18.1)$ & \multirow{2}{*}{5.926} & \multirow{2}{*}{0.015} \\
\hline Low & $205(89.9)$ & $23(10.1)$ & & \\
\hline \multicolumn{5}{|l|}{ Employment status } \\
\hline Working & $117(78.5)$ & $32(21.5)$ & \multirow{2}{*}{10.182} & \multirow{2}{*}{0.001} \\
\hline Not working & $278(89.4)$ & $33(10.6)$ & & \\
\hline Mean household income (RM) & & & & \\
\hline$<770$ & $152(91.0)$ & $15(9.0)$ & 6.568 & 0.010 \\
\hline$\geq 770$ & $243(82.9)$ & $50(17.1)$ & 0.508 & 0.010 \\
\hline Household size (person) & & & & \\
\hline$\geq 5$ & $138(83.1)$ & $28(16.9)$ & 1761 & 0185 \\
\hline$<5$ & $257(87.4)$ & $37(12.6)$ & $1 . / 61$ & 0.185 \\
\hline Distance from health facilities (kil & & & & \\
\hline$\geq 5$ & $206(88.0)$ & $28(16.0)$ & 1.165 & 0.280 \\
\hline$<5$ & $189(83.6)$ & $37(16.4)$ & & \\
\hline Having transportation & & & & \\
\hline Yes & $376(85.5)$ & $64(14.5)$ & 1537 & 0215 \\
\hline No & $19(95.0)$ & $1(5.0)$ & 1.537 & 0.215 \\
\hline Duration of illness (years) & & & & \\
\hline$>5$ & $187(78.6)$ & $51(21.4)$ & 21.024 & $<0.001$ \\
\hline$\leq 5$ & $208(93.7)$ & $14(6.3)$ & 21.024 & \\
\hline Comorbidity & & & & \\
\hline Yes & $131(74.9)$ & $44(25.1)$ & 31181 & \\
\hline No & $264(92.6)$ & $21(7.4)$ & 31.181 & $<0.001$ \\
\hline Family history of diabetes mellitus & & & & \\
\hline Yes & $165(78.6)$ & $45(21.4)$ & 18.968 & $<0.001$ \\
\hline No & $230(92.0)$ & $20(8.0)$ & 18.908 & $<0.001$ \\
\hline Complication of diabetes mellitus & & & & \\
\hline Yes & $169(85.4)$ & $29(14.6)$ & 0.331 & 0.595 \\
\hline No & $226(86.3)$ & $36(13.7)$ & 0.331 & 0.595 \\
\hline Early treatment at diagnosis & & & & \\
\hline Yes & $199(89.6)$ & $23(10.4)$ & 15.120 & $<0.001$ \\
\hline No & $196(82.4)$ & $42(17.6)$ & 15.120 & $<0.001$ \\
\hline Family support & & & & \\
\hline High & $223(88.1)$ & $30(11.9)$ & 2416 & 0.120 \\
\hline low & $172(83.1)$ & $35(16.9)$ & & \\
\hline Knowledge of diabetes mellitus & & & & \\
\hline Good & $226(85.9)$ & $37(14.1)$ & 0122 & 0727 \\
\hline Poor & $169(85.8)$ & $28(14.2)$ & 0.122 & 0.121 \\
\hline Perception of respondent toward $\mathrm{r}$ & & & & \\
\hline Positive & $152(84.9)$ & $27(15.1)$ & 0219 & 0639 \\
\hline Negative & $243(86.5)$ & $38(15.5)$ & 0.219 & 0.039 \\
\hline Perception of respondent towards & & & & \\
\hline Positive & $133(82.1)$ & $29(17.9)$ & 2.930 & 0.087 \\
\hline Negative & $262(87.9)$ & $36(12.1)$ & 2.930 & \\
\hline
\end{tabular}


TABle 3: Continued.

\begin{tabular}{|c|c|c|c|c|}
\hline \multirow{2}{*}{ Variables } & \multicolumn{2}{|c|}{ Health seeking behaviour } & \multirow[b]{2}{*}{$\chi$} & \multirow{2}{*}{$P$ value } \\
\hline & Appropriate $(n / \%)$ & Inappropriate $(n / \%)$ & & \\
\hline \multicolumn{5}{|c|}{ Perception of respondent towards benefit and barriers of preventive behaviour } \\
\hline Positive & $81(87.1)$ & $12(12.9)$ & \multirow{2}{*}{0.145} & \multirow{2}{*}{0.749} \\
\hline Negative & $314(85.6)$ & $53(14.4)$ & & \\
\hline \multicolumn{5}{|l|}{ Method of DM being diagnosed } \\
\hline Medical screening at community level & $26(86.7)$ & $4(13.3)$ & \multirow{7}{*}{16.120} & \multirow{7}{*}{0.013} \\
\hline Medical screening at health facilities & $115(92.7)$ & $9(7.3)$ & & \\
\hline Own initiatives & $103(84.4)$ & $19(15.6)$ & & \\
\hline Medical checkup (preemployment/haji) & $27(75.0)$ & $9(25.0)$ & & \\
\hline Getting treatment for symptom of DM & $62(89.9)$ & $7(10.1)$ & & \\
\hline Admitted to hospital due to complication of DM & $39(83.0)$ & $8(17.0)$ & & \\
\hline Medical screening 6 weeks postpartum & $23(71.9)$ & $9(28.1)$ & & \\
\hline
\end{tabular}

TABLE 4: Logistic regression predicting likelihood of appropriate health seeking behavior.

\begin{tabular}{|c|c|c|c|c|c|c|}
\hline Characteristic & $\beta$ & SE & WALD & $P$ value & $\operatorname{Exp} \beta$ & $95 \% \mathrm{CI}$ \\
\hline Constant & 2.394 & 0.346 & 47.822 & $<0.001$ & 10.953 & \\
\hline \multicolumn{7}{|l|}{ Age (years) } \\
\hline $\begin{array}{l}\geq 35 \\
<35\end{array}$ & 0.956 & 0.420 & 5.174 & 0.023 & $\begin{array}{l}1.00 \\
2.60\end{array}$ & $1.14-5.92$ \\
\hline \multicolumn{7}{|l|}{ Comorbidity } \\
\hline $\begin{array}{l}\text { Yes } \\
\text { No }\end{array}$ & 1.212 & 0.318 & 14.527 & $<0.001$ & $\begin{array}{l}1.00 \\
3.15\end{array}$ & $1.66-5.98$ \\
\hline \multicolumn{7}{|c|}{$\begin{array}{l}\text { Family history of diabetes } \\
\text { mellitus }\end{array}$} \\
\hline $\begin{array}{l}\text { Yes } \\
\text { No }\end{array}$ & 1.147 & 0.328 & 12.281 & $<0.001$ & $\begin{array}{l}1.00 \\
3.36\end{array}$ & $1.80-6.27$ \\
\hline \multicolumn{7}{|c|}{$\begin{array}{l}\text { Distance from health } \\
\text { facilities (kilometre) }\end{array}$} \\
\hline $\begin{array}{l}<5 \\
\geq 5\end{array}$ & 0.699 & 0.312 & 5.035 & 0.025 & $\begin{array}{l}1.00 \\
2.01\end{array}$ & $1.08-3.70$ \\
\hline \multicolumn{7}{|c|}{$\begin{array}{l}\text { Seeking treatment upon } \\
\text { diagnosis (within } 24 \text { hours) }\end{array}$} \\
\hline $\begin{array}{l}\text { Yes } \\
\text { No }\end{array}$ & 0.962 & 0.337 & 8.156 & 0.004 & $\begin{array}{l}2.62 \\
1.00\end{array}$ & $1.35-5.07$ \\
\hline \multicolumn{7}{|c|}{ Duration of illness (years) } \\
\hline $\begin{array}{l}>5 \\
\leq 5\end{array}$ & 1.222 & 0.355 & 11.860 & 0.001 & $\begin{array}{l}1.00 \\
3.40\end{array}$ & $1.69-6.08$ \\
\hline \multicolumn{7}{|c|}{$\begin{array}{l}\text { Complication of diabetes } \\
\text { mellitus }\end{array}$} \\
\hline $\begin{array}{l}\text { Yes } \\
\text { No }\end{array}$ & -0.584 & 0.318 & 3.369 & 0.066 & $\begin{array}{c}1.00 \\
0.588\end{array}$ & $0.30-1.04$ \\
\hline Family suppor & & & & & & \\
\hline $\begin{array}{l}\text { low } \\
\text { high }\end{array}$ & -1.112 & 0.456 & 5.949 & 0.015 & $\begin{array}{l}1.00 \\
2.56\end{array}$ & $1.25-7.69$ \\
\hline
\end{tabular}

$R^{2}=0.789$ (Hosmer and Lemeshow), 0.25 (Cox and Snell), and 0.38 (Nagelkerke). Model $\chi^{2}(28)=136, P<0.001$. 


\section{Conflict of Interests}

The authors declare that there is no conflict of interests regarding the publication of this paper.

\section{Acknowledgments}

The authors would like to thank the Research and Ethics Committee, National University of Malaysia, for funding this research. The authors also deeply appreciate the help and participation of villagers from Tanjong Karang, Selangor, with the data collection.

\section{References}

[1] WHO, Diabetes Mellitus, World Health Organization, Geneva, Switzerland, 2011, http://www.who.int/mediacentre/factsheets/ fs $311 /$ en/.

[2] P. Zimmet, K. G. Alberti, and J. Shaw, "Global and societal implications of the diabetes epidemic," Nature, vol. 414, no. 6865, pp. 782-787, 2001.

[3] A. F. Amos, D. J. McCarty, and P. Zimmet, "The rising global burden of diabetes and its complications: estimates and projections to the year 2010," Diabetic Medicine, vol. 14, no. 12, pp. S7S85, 1997.

[4] S. Wild, G. Roglic, A. Green, R. Sicree, and H. King, "Global prevalence of diabetes: estimates for the year 2000 and projections for 2030," Diabetes Care, vol. 27, no. 5, pp. 1047-1053, 2004.

[5] Ministry of Health-Epidemiology and Disease Control Division, National Health Survey 2004, Ministry of Health, Singapore, 2004.

[6] Ministry of Health, Clinical Practice Guidelines Diabetes Mellitus, MOH Clinical Practice Guidelines 3/2006, Ministry of Health, Singapore, 2006, http://www.moh.gov.sg/cpg.

[7] M. Mafauzy, "Diabetes in Malaysia," Journal of Medicine Malaysia, vol. 61, no. 4, pp. 397-398, 2006.

[8] Institute for Public Health, National Institute of Health, and Ministry of Health, The Fourth National Health And Morbidity Survey (NHMS IV), Institute for Public Health, National Institute of Health and Ministry of Health, Putrajaya, Malaysia, 2011.

[9] S. Hausmann-Mueala, J. Muela Ribera, and I. Nyamongo, "Health-seeking behaviour and the health system response," in Disease Control Priorities Project (DCPP), Working Paper no. 14, 2003, http://pass-international.org/site/images/stories/ publications/DCPP_Working_Paper_14_No_Health_seeking_ behaviour_and_the_health_system_response.pdf.

[10] K. M. Cummings, M. H. Becker, and M. C. Maile, "Bringing the models together: an empirical approach to combining variables used to explain health actions," Journal of Behavioral Medicine, vol. 3, no. 2, pp. 123-145, 1980.

[11] A. Kroeger, "Anthropological and socio-medical health care research in developing countries," Social Science and Medicine, vol. 17, no. 3, pp. 147-161, 1983.

[12] R. Remli and S. C. Chan, "Use of complementary medicine among diabetic patient in a public primary care clinic in Ipoh," Medical Journal of Malaysia, vol. 58, no. 5, pp. 688-693, 2003.

[13] Ministry of Health Malaysia, Clinical Practices Guideline, Management of Type 2 Diabetes Mellitus, 2009.

[14] M. A. Yunus, M. M. T. Nasir, M. Z. Nor Afiah, M. S. Sherina, and M. S. Leong, "Prevalence of self medication and traditional medication among residents in a village in Sepang, Selangor," Malaysian Journal of Public Health Medicine, vol. 4, no. 2, pp. 30-33, 2003.

[15] National Health and Morbidity Survey, Annual report, Ministry of Health Malaysia, 2006.

[16] World Health Organization and Regional Office for the Western Pacific, "2004 Country Health Information Profile: Malaysia," http://www.who.int/gho/countries/mys.pdf?ua=1.

[17] S. Krishnaswamy, K. Subramaniam, W. Y. Low et al., "Factors contributing to utilization of health care services in Malaysia: a population-based study," Asia-Pacific Journal of Public Health, vol. 21, no. 4, pp. 442-450, 2009.

[18] B. Khongbuh, I. Walia, and S. Kapoor, "Prevalence of diabetes and treatment seeking behaviour among adult population at Village Dhanas, U.T. Chandigarh," Nursing and Midwifery Research Journal, vol. 1, no. 3, pp. 138-143, 2005.

[19] K. Hjelm and F. Atwine, "Health-care seeking behaviour among persons with diabetes in Uganda: an interview study," BMC International Health and Human Rights, vol. 11, no. 1, article 11, 2011.

[20] P. A. Bourne, "Socio-demographic determinants of health care-seeking behaviour, self-reported illness and self-evaluated health status in Jamaica," International Journal of Collaborative Research on Internal Medicine and Public Health, vol. 1, no. 4, pp. 101-130, 2009.

[21] L. Y. Wong and M. P. Toh, "Understanding of diabetes mellitus and health-preventive behaviour among Singaporeans," Annals of the Academy of Medicine Singapore, vol. 38, no. 6, pp. 478486, 2009. 


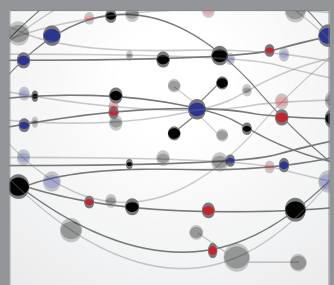

The Scientific World Journal
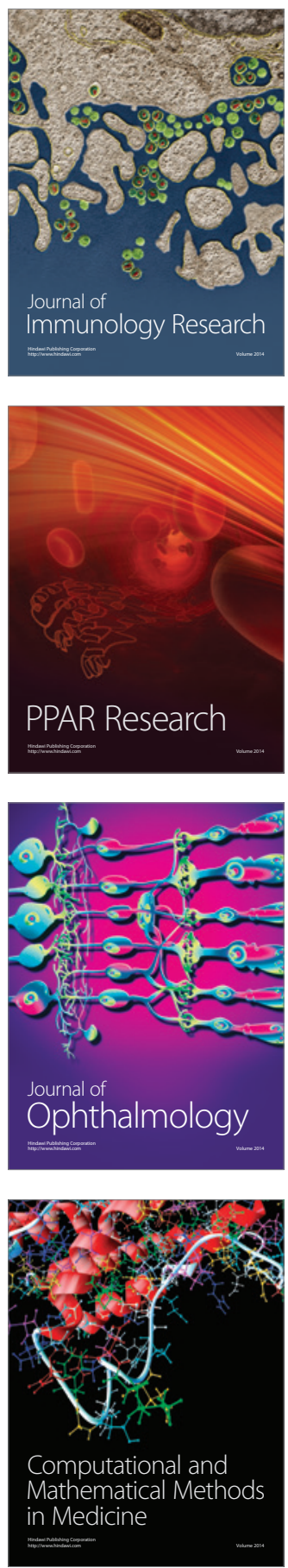

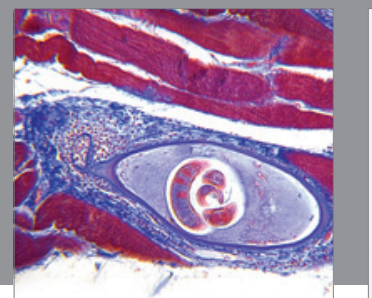

Gastroenterology

Research and Practice
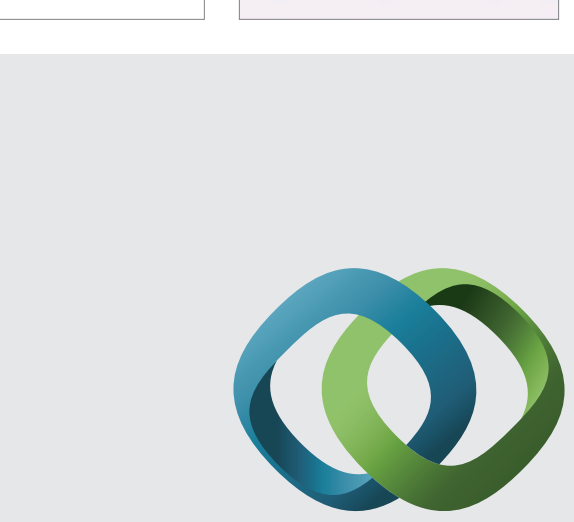

\section{Hindawi}

Submit your manuscripts at

http://www.hindawi.com
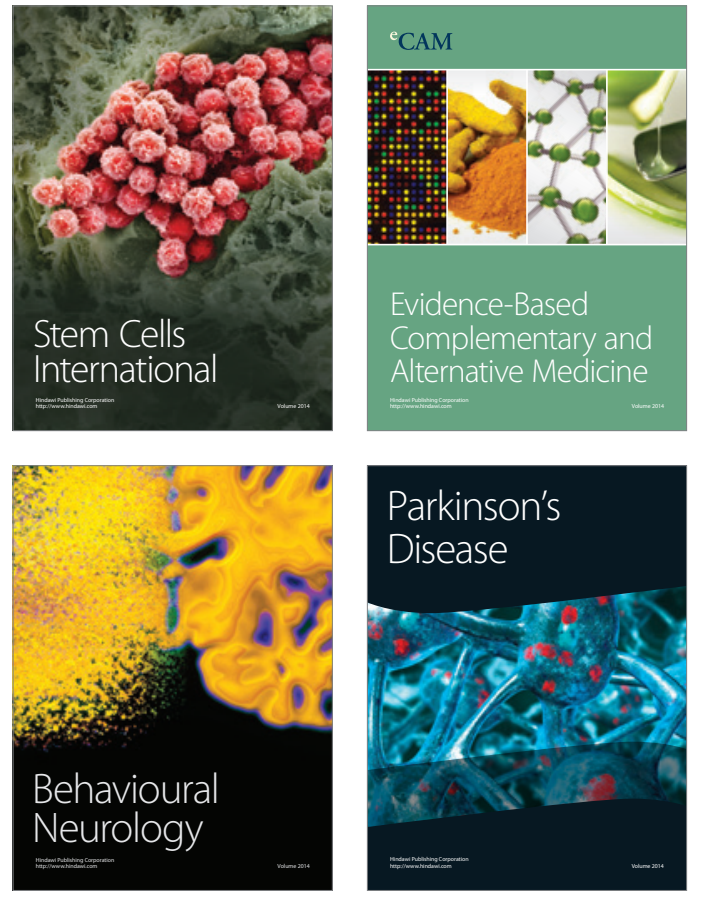
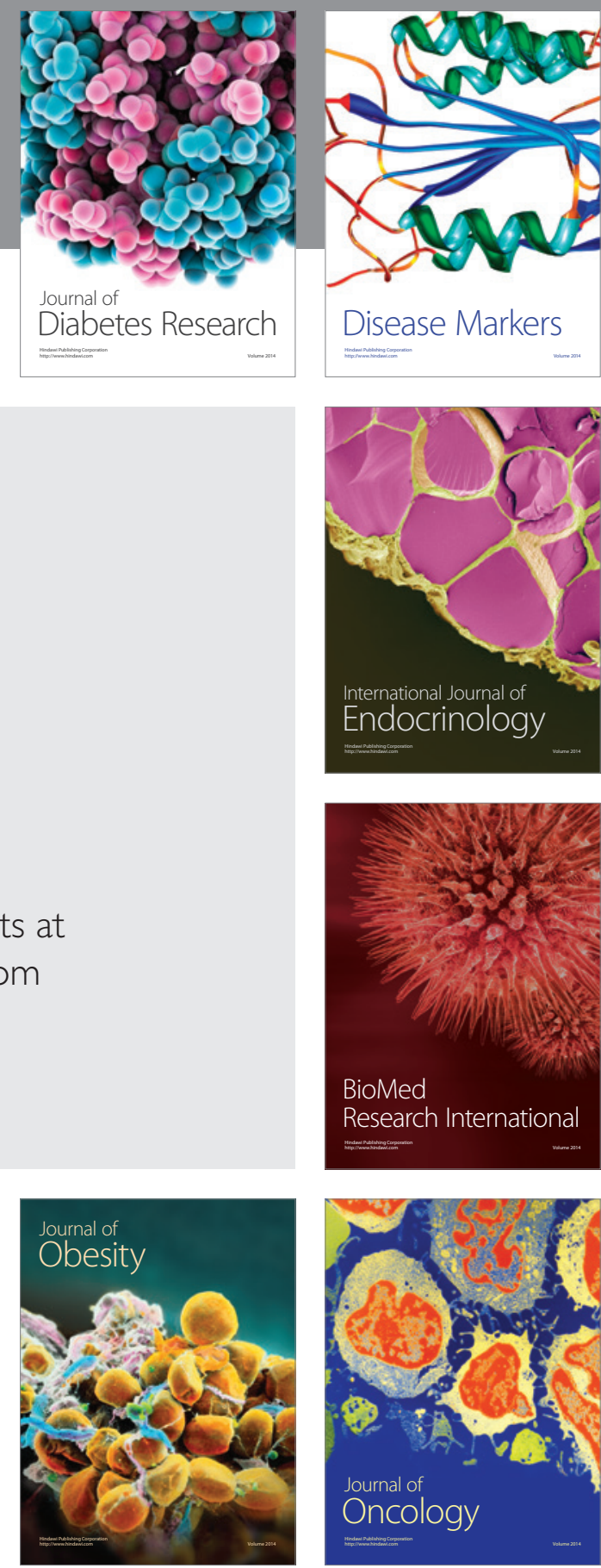

Disease Markers
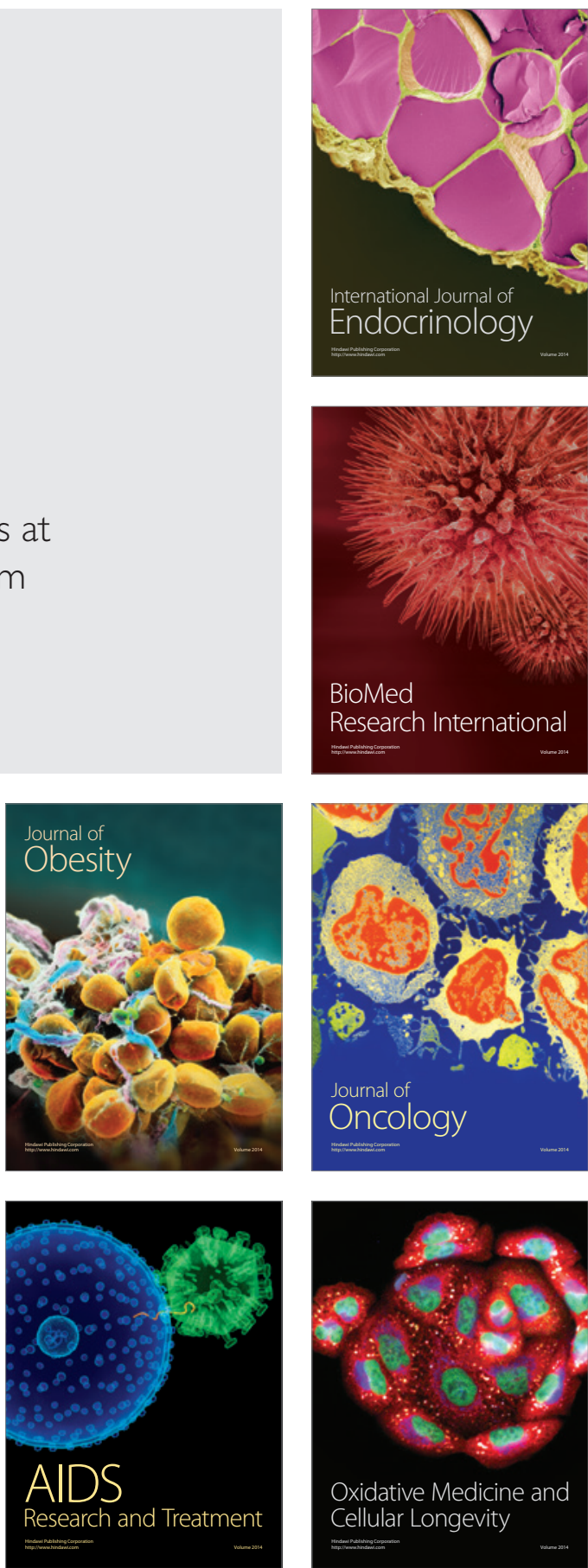